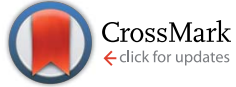

Cite this: RSC Adv., 2015, 5, 25634

Received 18th December 2014

Accepted 3rd March 2015

DOI: $10.1039 / c 4 r a 16637 j$

www.rsc.org/advances

\section{Development of hybrid composites for automotive applications: effect of addition of SEBS on the morphology, mechanical, viscoelastic, crystallization and thermal degradation properties of PP/PS $-x \mathrm{GnP}$ composites}

\author{
Jyotishkumar Parameswaranpillai, ${ }^{* a}$ George Joseph, ${ }^{a}$ K. P. Shinu, ${ }^{a}$ Seno Jose, ${ }^{b}$ \\ Nisa V. Salim ${ }^{c}$ and Nishar Hameed ${ }^{\star c}$
}

\begin{abstract}
In this article, we report on a simple and cost effective approach for the development of light-weight, super-tough and stiff material for automotive applications. Nanocomposites based on PP/PS blend and exfoliated graphene nanoplatelets ( $x \mathrm{GnP}$ ) were prepared with and without SEBS. Mechanical, crystallization and thermal degradation properties were determined and correlated with phase morphology. The addition of $x \mathrm{GnP}$ to PP/PS blend increased the tensile modulus at the expense of toughness. The presence of $x \mathrm{GnP}$ increased the enthalpy of crystallization and enthalpy of fusion of PP in the blends, without affecting segmental mobility and thermal stability. Addition of polystyrene-blockpoly(ethylene-ran-butylene)-block-polystyrene (SEBS) improved the toughness of PP/PS blends, but decreased the stiffness. The incorporation of $x \mathrm{GnP}$ into this ternary blend generated a super-tough material with improved stiffness and tensile elongation, suitable for automotive applications. It is observed that the presence of SEBS diminished the tendency of agglomeration of $x \mathrm{GnP}$ and their unfavorable interactions with thermoplastics, which in turn reduced the internal friction in the matrix.
\end{abstract}

\section{Introduction}

Polymer blending is a simple but effective method to develop advanced polymeric materials. The properties of the blends can be manipulated according to the end use, by changing the concentration of the component polymers. Polypropylene (PP) is an important commodity plastic. Blending of PP with rigid polymers such as polystyrene (PS) and polyphenylene ether (PPE) improves its strength and stiffness, at the expense of toughness. ${ }^{1-4}$ However, these blends exhibit poor mechanical properties due to their inherent immiscibility and incompatibility. ${ }^{5}$ It is reported that these problems can be alleviated by the use of compatibilizing agents, which locate at the interface and reduce the unfavorable interfacial interactions $\mathrm{s}^{6-8}$ and or retard the rate of coalescence process, thereby reducing the particle size and improving the blend properties. ${ }^{\mathbf{9 - 1 4}}$

Recently researchers are interested in using nanofillers or polymer grafted nanofillers as compatibilizers for polymer blends. ${ }^{15-19}$ You et al. ${ }^{20}$ synthesized polypropylene-graft-reduced

${ }^{a}$ Department of Polymer Science and Rubber Technology, Cochin University of Science and Technology, Cochin 682022, Kerala, India. E-mail: jyotishkumarp@gmail.com ${ }^{b}$ Department of Chemistry, Government College Kottayam, Kerala, India 686013

${ }^{c}$ Carbon Nexus, Institute for Frontier Materials, Deakin University, Waurn Ponds Campus, Geelong, VIC, 3220, Australia.E-mail: nishar.hameed@deakin.edu.au graphene oxide (PP-g-rGO) and used it as a novel compatibilizer for PP/PS immiscible polymer blends. Krishnan et al. ${ }^{21}$ studied the effect of modified kaolin clays on the mechanical properties of PP/PS 80/20 blends and observed good improvement in mechanical and thermal properties. Elias et al. ${ }^{22}$ studied the effect of two types of fumed silica (hydrophilic and hydrophobic) on the morphology of PP/PS 70/30 blends and found a significant reduction in the PS droplets size in the presence of both types of silica.

In a recent work, Al-Saleh et al. ${ }^{23}$ have successfully localized carbon black (CB) at the interface of PP/PS blend by adding SBS copolymer and reduced the percolation threshold of CB-filled (70/30) PP/PS blend. Tiwari et al. ${ }^{24}$ studied effect of modified clay on the morphology, phase stability and mechanical properties of PP/PS blends. Maleated polypropylene (PP- $g$-MA) was used to preferentially promote dispersion of the organoclay in the PP matrix.

In an earlier work, we reported on the compatibility and thermo-mechanical properties of $\mathrm{PP}-x \mathrm{GnP}$ composites in the presence and absence of SEBS. ${ }^{25}$ The study revealed synergistic effects of SEBS and $x \mathrm{GnP}$ on the impact properties of PP. It was also found that internal friction in the sample decreased considerably by the addition of SEBS in PP- $x \mathrm{GnP}$ composites. In this context, this study aims at investigating the effect of addition of SEBS on the physical and mechanical 
properties of the PP/PS- $x \mathrm{GnP}$ composites. The addition of amorphous PS into crystalline PP is not only intends to increase the strength but also justifies the use of SEBS, which tends to decrease the internal friction between the components in the blends and reduce the tendency of agglomeration of $x \mathrm{GnP}$. The amount of SEBS, which plays a key role in the interaction between the PP, PS and $x \mathrm{GnP}$ in PP/PS blends, is set as $20 \mathrm{wt} \%$ to obtain the matrix with optimum stiffness and toughness.

\section{Experimental}

\section{Materials and preparation of blends}

PP homopolymer, grade 1110 MAS with a melt flow index of $16.3 \mathrm{~g}$ per $10 \mathrm{~min}\left(230^{\circ} \mathrm{C}\right.$ per $\left.5 \mathrm{~kg}\right)$ having density $0.9 \mathrm{~g} \mathrm{~cm}^{-3}$ was supplied by Indian Oil Corporation. PS grade Polystyrol $147 \mathrm{~F}$ GR21, having density $1.05 \mathrm{~g} \mathrm{~cm}^{-3}$ was supplied by Styrolution India Pvt. ltd. PS has a melt flow index of $6.5 \mathrm{~g}$ per $10 \mathrm{~min}$ $\left(200{ }^{\circ} \mathrm{C}\right.$ per $5 \mathrm{~kg}$ ). Compatibilizer, polystyrene-block-poly(ethylene-ran-butylene)-block-polystyrene (SEBS) with average $M_{\mathrm{w}} \sim 118000$ by GPC, contains $>0.03 \%$ antioxidant as inhibitor, was obtained from Sigma Aldrich. Exfoliated graphene nanoplatelets $(x \mathrm{GnP})$ - grade $\mathrm{M}$ with $99.5 \%$ carbon was obtained from XG Science, Inc. The $x \mathrm{GnP}$ have an average thickness of 6 to 8 nanometers and surface area of $120-150 \mathrm{~m}^{2} \mathrm{~g}^{-1}$. PP/PS (80/20) blends were prepared by melt mixing, using Thermo Haake Polylab QC system equipped with roller rotors. The mixing was done at $180{ }^{\circ} \mathrm{C}$ with a rotor speed of $50 \mathrm{rpm}$ for 8 minutes. For making PP/PS $-x \mathrm{GnP}$ composites, PP and PS was melt mixed for two minutes, followed by the addition of $x \mathrm{GnP}$. Similarly, for compatibilized composites initially PP and PS were melt mixed for two minutes, followed by the addition of compatibilizer and $x \mathrm{GnP}$. The total mixing time is 8 minutes. The concentration of $x \mathrm{GnP}$ used was $0.1,0.3,0.5$, and $1 \mathrm{wt} \%$. Each component is added one by one in the above mentioned order, once the torque becomes minimum. The resulting blends and composites were hot pressed into sheets and cut in to pieces and injection molded in a DSM explore, Micro 12cc injection molding machine at $190{ }^{\circ} \mathrm{C}$, for preparing the test specimens for impact and tensile testing as per relevant ISO standards.

\section{Characterization}

Scanning electron microscopy (SEM). The morphology of the blends and composites was examined with a Zeiss Supra 55VP field emission gun scanning electron microscope (SEM) at an activation voltage of $5 \mathrm{kV}$ with a working distance of $10 \mathrm{~mm}$. The cryo-fractured surfaces were coated with thin layers of gold to avoid charging.

Dynamic mechanical analysis (DMA). Dynamic mechanical analysis was carried out using DMA Q-800 TA instruments, to study the viscoelastic behavior of PP/PS blends. Rectangular specimens of $60 \times 12 \times 3 \mathrm{~mm}^{3}$ dimensions were used for the study. Analysis was done using a dual cantilever clamp at a dynamic frequency of $1 \mathrm{~Hz}$ in the temperature range 35 to $130{ }^{\circ} \mathrm{C}$ with a ramp of $3{ }^{\circ} \mathrm{C} \mathrm{min}^{-1}$.
Thermo gravimetric analysis (TGA). The thermal stability of the polymer blends was analysed using a TGA-Q-50 TA instrument in nitrogen atmosphere. The sample weight of about 5-7 mg was used and test was carried out from room temperature to $600{ }^{\circ} \mathrm{C}$ at a heating rate of $20{ }^{\circ} \mathrm{C} \mathrm{min}^{-1}$.

Differential scanning calorimetry (DSC). Thermal properties were determined using Mettler Toledo DSC 822e differential scanning calorimetry. The parameters such as crystallization temperature $\left(T_{\mathrm{c}}\right)$, melting temperature $\left(T_{\mathrm{m}}\right)$, total enthalpy of crystallization $\left(\Delta H_{\mathrm{c}}\right)$, total enthalpy of fusion $\left(\Delta H_{\mathrm{f}}\right)$ and $X_{\mathrm{c}}(\%)$ percentage crystallinity are derived from the DSC thermogram. Samples of approximately $10 \mathrm{mg}$ were placed into ceramic pans and the tests were performed in a dry nitrogen atmosphere (flow rate of $20 \mathrm{~mL} \mathrm{~min}^{-1}$ ). The heating was done from -50 to $200{ }^{\circ} \mathrm{C}$ at a heating rate of $10{ }^{\circ} \mathrm{C} \mathrm{min}^{-1}$, followed by cooling to room temperature at $10{ }^{\circ} \mathrm{C} \mathrm{min}^{-1}$. The melting and crystallization were determined from the DSC heating and cooling curves.

$\Delta H_{\mathrm{f}}$ and $\Delta H_{\mathrm{c}}$ were obtained from the areas under the melting and crystallization peaks. Indium and silver samples were used as calibration standards.

\section{Mechanical properties}

The tensile properties of the samples were measured using a universal testing machine (Tinius Olsen) model H $50 \mathrm{KT}$ at a cross head speed of $50 \mathrm{~mm} \mathrm{~min}^{-1}$, according to ISO 527 on dumbbell shaped specimens. The sample dimensions were $75 \times 5 \times 2 \mathrm{~mm}^{3}$. The span length used was $55 \mathrm{~mm}$. Impact testing was carried out according to ISO 180 using a Resil impactor junior. Unnotched samples were used for testing. The sample dimensions were $80 \times 10 \times 4 \mathrm{~mm}^{3}$.

\section{Results and discussion}

\section{Mechanical properties}

The incorporation of $x \mathrm{GnP}$ has no significant effect on the impact strength and tensile strength of PP/PS blend (Fig. 1a). Although the tensile elongation of the blend decreased by about $40 \%$, tensile modulus increased by about $15 \%$ (Fig. 1b). The results reveal that graphene nanoplatelets have no reinforcement effect in PP/PS blends, but suggest that the PP/PS interfaces are so weak that they cannot transfer stresses between the PP matrix and the PS dispersed phase, even in the presence of $x \mathrm{GnP}$. This indicates that nanoparticles are not well dispersed in the blend or blend interface and contribute nothing to diminish the unfavourable cross-correlations between PP and PS chains in the blend. Reduction in tensile elongation with increasing concentration of $x \mathrm{GnP}$ in the blend implies their greater tendency for agglomeration. An increase in tensile modulus is not unexpected as it is measured at very low strain level.

SEM micrographs (Fig. 2) demonstrate the phase morphology of the blends with and without nanoplatelets. Presence of $x \mathrm{GnP}$ have no significant impact on the phase morphology of the blends, except that the dispersed particle size decreased. All the blends showed two-phase, coarse and non-uniform morphology 


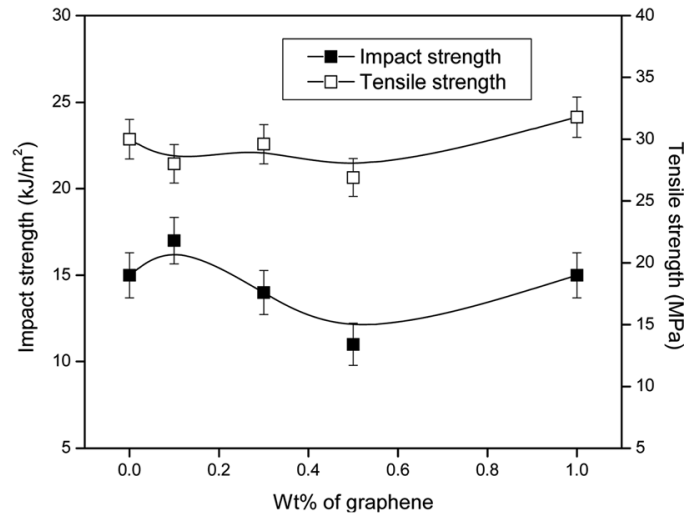

(a)

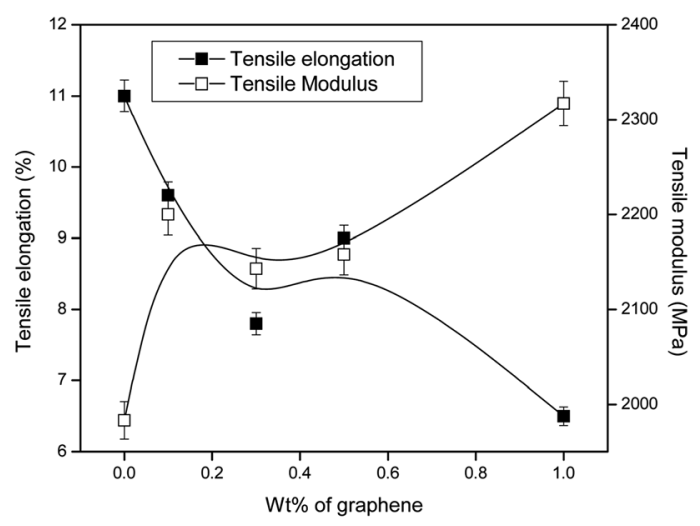

(b)

Fig. 1 Mechanical properties of PP/PS $-x$ GnP composites.

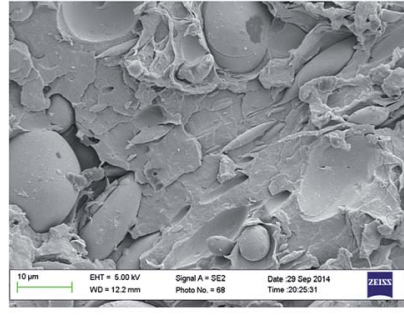

(a) PS/PP blend

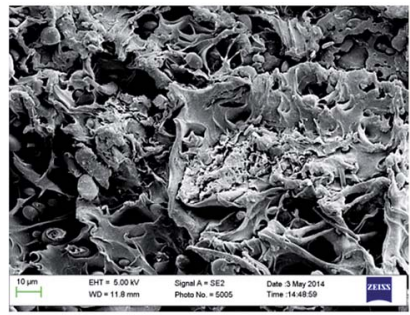

(c) $0.3 \mathrm{wt} \%$ of $\mathrm{xGnP}$

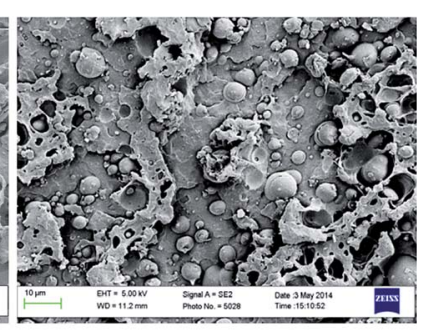

(b) $0.1 \mathrm{wt} \%$ of $\mathrm{xGnP}$

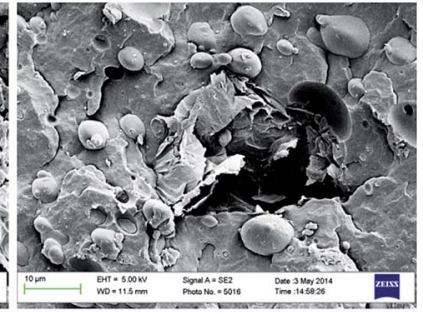

(d) $1 \mathrm{wt} \%$ of $\mathrm{xGnP}$
Fig. 2 Scanning electron micrographs of PP/PS $-x \mathrm{GnP}$ composites. indicating a high interfacial tension and coalescence due to the absence of favorable interfacial interactions.

It is obvious from Fig. 3a that the addition of SEBS increased the impact strength of PP/PS blends appreciably (ca. 200\%) and decreased the tensile strength only marginally. It should be noted that the presence of nanoplatelets in the ternary system made no significant change in impact strength, except at highest concentration ( $1 \mathrm{wt} \%)$. Similarly, tensile strength of the ternary system is only slightly affected by the presence of $x \mathrm{GnP}$. It is important to note that addition of SEBS in PP/PS blends resulted in a drastic reduction in tensile modulus ( $\mathrm{ca}$. 40\%), which may severely restrict its end use applications due to poor stiffness. But the incorporation of even $0.1 \mathrm{wt} \%$ of $x \mathrm{GnP}$ effectively recompensed this serious constraint by enhancing the tensile modulus of the ternary system by more than $15 \%$. Tensile elongation registered a remarkable improvement. Addition of SEBS into $\mathrm{PP} / \mathrm{PS}$ blends increased the tensile elongation of the blends by $c a$. $250 \%$. More importantly, incorporation of only $0.1 \mathrm{wt} \%$ of $x \mathrm{GnP}$ increased the tensile elongation of the ternary system by about 65\% (ca. 500\% increase compared to the PP/PS blends). Thus PP/PS-SEBS- $x$ GnP (0.1 wt $\%$ ) composites exhibit good impact strength ( $c a .140 \%$ greater than PP/PS blends), excellent tensile elongation ( $c a .500 \%$ greater than PP/PS blend), reasonably good strength (ca. 15\% less than PP/PS blends) and stiffness (ca. 25\%

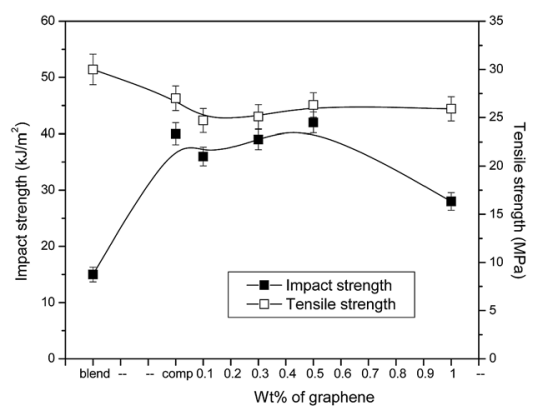

(a)

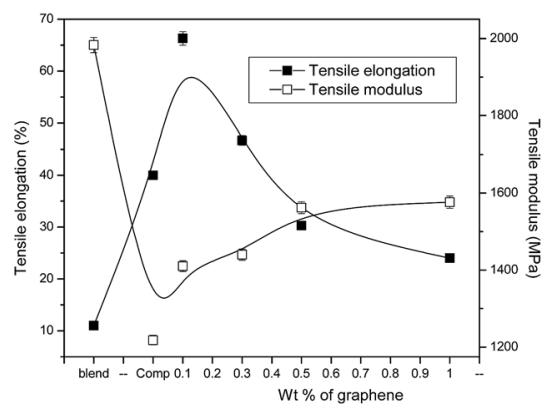

(b)

Fig. 3 Mechanical properties of PP/PS-SEBS $-x$ GnP composites. 
less than PP/PS blends). This makes this composite material suitable for automotive applications.

SEM micrographs of PP/PS-SEBS- $x$ GnP composites (Fig. 4) illustrate the dramatic change in the phase morphology, in the presence of SEBS. The matrix/droplet type morphology of $\mathrm{PP} / \mathrm{PS}-x \mathrm{GnP}$ composites is transformed to an interpenetrating, co-continuous type morphology. It is important to mention that the presence of SEBS will decrease the unfavourable crosscorrelations between the PP/PP chains. Note that the SEBS is partially miscible with the PS phase (due to the presence of styrene units) and its segments exhibit less unfavourable crosscorrelations with the PP chains (due to the presence of ethylene units). Thus SEBS strengthens the interface between the

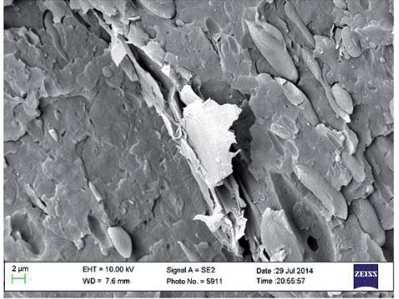

(a) $0.1 \mathrm{wt} \%$ of $\mathrm{xGnP}$

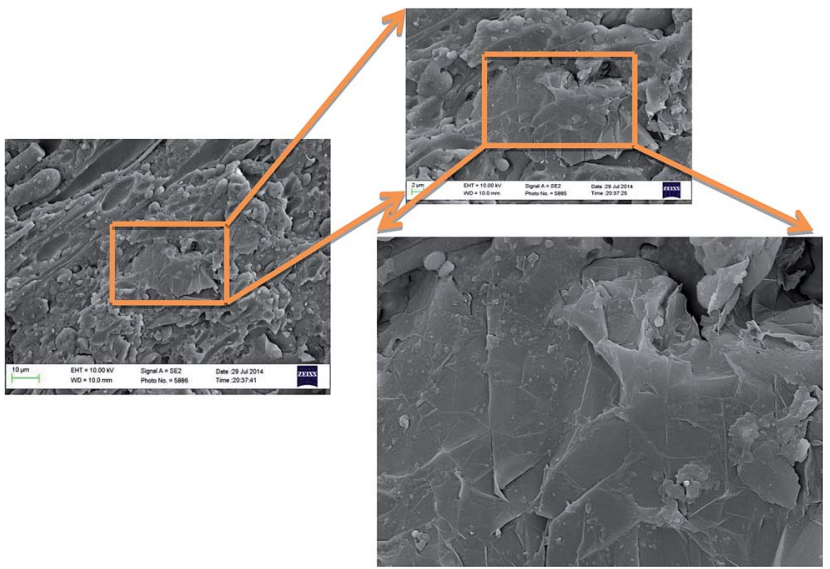

(c) $0.5 \mathrm{wt} \%$ of $\mathrm{xGnP}$

Fig. 4 SEM micrographs of PP/PS-SEBS $-x$ GnP composites. component polymers and improves the interfacial adhesion. The reinforced interface can transfer the stress between the components more effectively and thus enhance the mechanical properties, except stiffness. Now, the incorporation of $x \mathrm{GnP}$ into this ternary system makes the difference. The nanoplatelets will diffuse through the polymer chains, finely disperse among the soft SEBS segments and enhance the overall stiffness of the system. A fraction of particles will find their locations at the polymer interface and fill the voids there, if any and contribute towards the strengthening of the interface. Thus the overall effect is a substantial reduction of the tendency of nanoparticles to undergo agglomeration.

\section{Viscoelastic properties}

The storage modulus of PP/PS blends (Fig. 5a) increased with the addition of $x \mathrm{GnP}$. The increase in storage modulus indicates increased stiffness attributed to the reinforcing effect of graphene, which is one of the stiffest known materials. ${ }^{26}$ Further, the graphene sheets are able to reduce the mobility of the polymer chains by interfering the segmental motion, which also contributes to the enhancement of the storage modulus. It is seen that the storage modulus decreases with temperature since the short range segmental motions that initially gave rise to the glass transition of PP occur very much faster. Note that the long range cooperative motion of chain segments that would result in translational motions of complete molecules is still restricted by the presence of chain entanglements which act as temporary cross links. The $T_{\mathrm{g}}$ of PS phase is observed as $110^{\circ} \mathrm{C}$, where the amplitude of vibrational motion of PS segments becomes greater, and eventually, the thermal energy becomes comparable to the potential energy barrier for the segment vibration.

The loss modulus profile of $\mathrm{PP} / \mathrm{PS}-x \mathrm{GnP}$ composites is shown in Fig. 5b. All nanocomposites exhibited higher loss modulus values compared to the neat PP/PS blends. This is expected, since excessive heat is generated by application of applied stress due to the filler-filler and filler polymer interactions. Thus more heat is dissipated from the nanocomposites. The main peak at around $114{ }^{\circ} \mathrm{C}$ corresponds to the $T_{\mathrm{g}}$ of the PS phase. From the loss modulus profile, it is clear that the incorporation of $x \mathrm{GnP}$ causes slight broadening of peak width

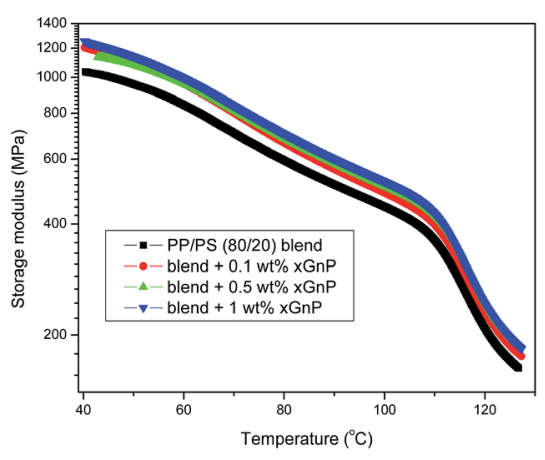

(a)

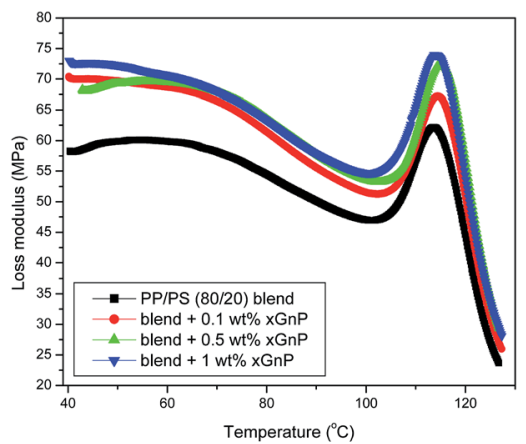

(b)

Fig. 5 Plot of (a) storage modulus and (b) loss modulus of PP/PS $-x$ GnP composites. 


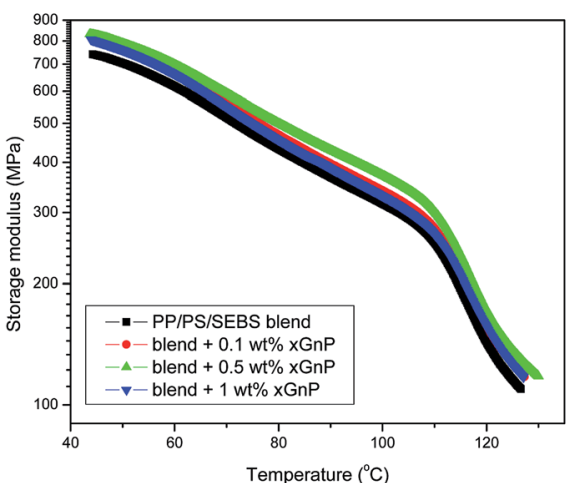

(a)

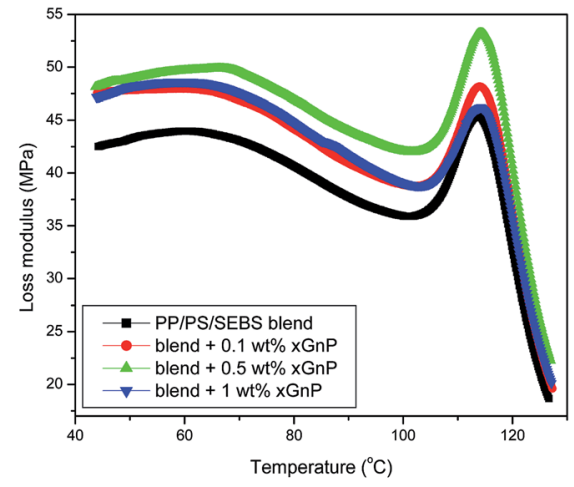

(b)

Fig. 6 Plot of (a) storage modulus and (b) loss modulus of PP/PS-SEBS blend and PP/PS-SEBS $-x$ GnP composites.

of the loss modulus curves. The peak broadening may be due to the interactions between the $x \mathrm{GnP}$ and the polymer. ${ }^{27}$ Note that the $T_{\mathrm{g}}$ of the PS phase was not affected by the addition of the $x \mathrm{GnP}$.

It is obvious that storage modulus values of ternary systems (Fig. 6a) are considerably lower than those of binary system
(Fig. 5). Thus the addition of SEBS decreased the stiffness of the system. The storage modulus of ternary blends increased with $x \mathrm{GnP}$ concentration, which implies an enhancement of stiffness by the incorporation of graphene platelets. It is also important to note that the loss modulus of ternary system increased with the addition of $x \mathrm{GnP}$. The higher loss modulus is

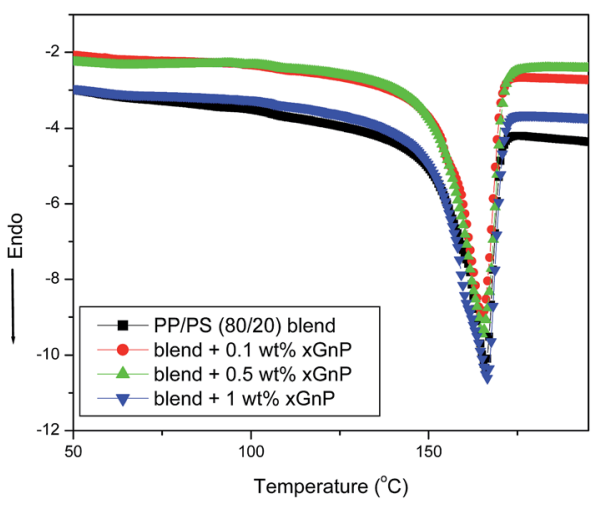

(a)

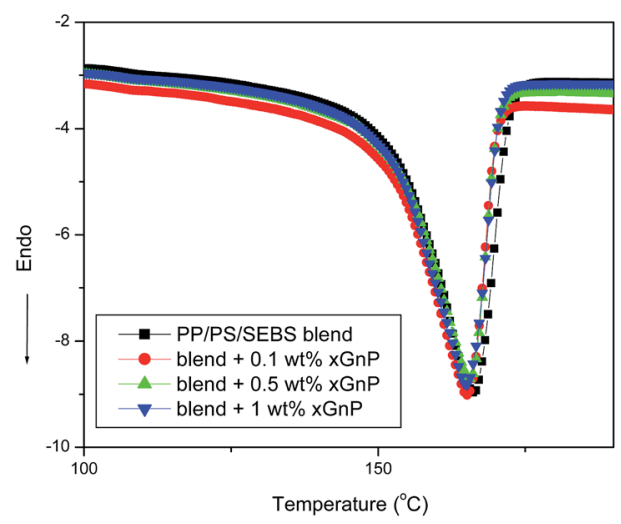

(c)

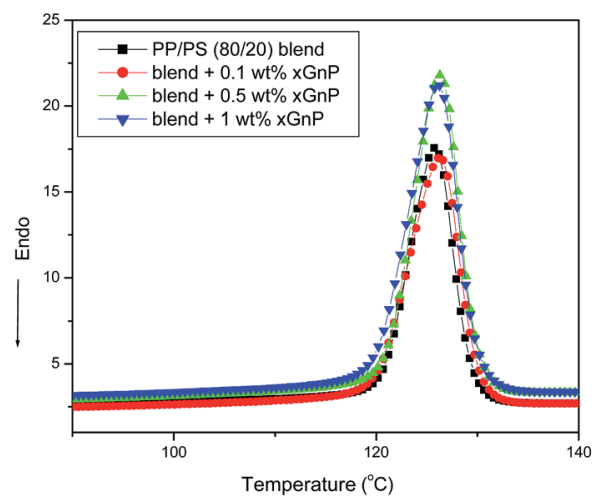

(b)

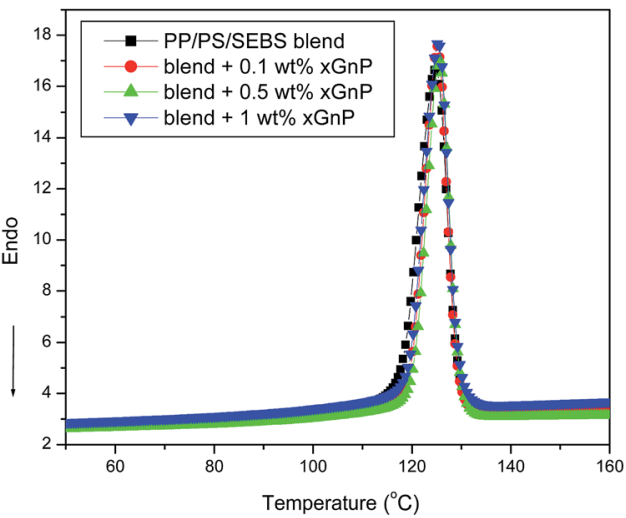

(d)

Fig. 7 (a) Heating and (b) cooling thermograms of PP/PS $-x$ GnP composites, (c) heating and (d) cooling thermograms of PP/PS-SEBS $-x G n P$ composites. 
due to the excessive heat generation due to friction, because of the polymer-filler interactions. But, the loss moduli of PP/PSSEBS- $x$ GnP composites are less than those of corresponding $\mathrm{PP} / \mathrm{PS}-x \mathrm{GnP}$ composites. This implies the overall reduction in internal friction or improvement in damping behavior of the composites.

\section{DSC measurements}

Melting and crystallization properties of binary and ternary systems with and without graphene computed from the DSC heating and cooling thermograms (Fig. 7) are summarized in Table 1. The parameters, melting point $\left(T_{\mathrm{m}}\right)$ and enthalpy of fusion $\left(\Delta H_{\mathrm{f}}\right)$ are estimated from the DSC heating curves while crystallization temperature $\left(T_{\mathrm{c}}\right)$ and enthalpy of crystallization $\left(\Delta H_{\mathrm{c}}\right)$ were determined from the cooling curves. The degree of crystallinity of nanocomposites can be determined using the equation:

$$
X_{\mathrm{c}}=\frac{\Delta H_{\mathrm{f}}}{\Delta H_{\max } \times W_{\text {poly }}} \times 100
$$

where $\Delta H_{\mathrm{f}}$ is the normalized enthalpy of fusion, $\Delta H_{\max }$ is the enthalpy of fusion for a theoretically $100 \%$ crystalline polymer and $W_{\text {poly }}$ is the weight fraction of PP in the blend. The term $\Delta H_{\max }$ is a reference value and represents the heat of fusion if the polymer is $100 \%$ crystalline, this value for PP is $207.1 \mathrm{~J} \mathrm{~g}^{-1}$.

From Table 1 , it can be seen that PP/PS- $x$ GnP composites exhibit greater value of $\Delta H_{\mathrm{m}}$ and $\Delta H_{\mathrm{c}}$, compared to neat PP. This indicates that $x \mathrm{GnP}$ plays an important role in accelerating the rate crystallization of the PP, particularly with $0.1 \mathrm{wt} \%$ of $x \mathrm{GnP}$. The percentage crystallinity value of PP increased from 40.3 to 45.6 with the addition of $0.1 \mathrm{wt} \%$ of $x \mathrm{GnP}$. From these results, it can be argued that a small fraction of graphene platelets can act as effective nucleating sites for the crystallization of PP. But, at higher concentrations of graphene the nucleation effect is reduced, indicating agglomeration of the $x \mathrm{GnP}$. The nucleating effect of $x \mathrm{GnP}$ was observed in several other studies. ${ }^{28-31}$ However, no significant change in $T_{\mathrm{m}}$ and $T_{\mathrm{c}}$ was observed by the addition of $x \mathrm{GnP}$. It is important to note that addition of $x \mathrm{GnP}$ in ternary systems has
Table 1 DSC summary of $T_{m}, T_{c}, \Delta H_{m}, \Delta H_{c}$ and $X_{c}$ for neat PP/PS, PP/ PS-SEBS, PP/PS $-x$ GnP and PP/PS-SEBS $-x$ GnP systems

\begin{tabular}{lccccc}
\hline$T_{\mathrm{m}}$ & $T_{\mathrm{m}}\left({ }^{\circ} \mathrm{C}\right)$ & $T_{\mathrm{c}}\left({ }^{\circ} \mathrm{C}\right)$ & $\begin{array}{l}\Delta H_{\mathrm{m}} \\
\left(\mathrm{J} \mathrm{g}^{-1}\right)\end{array}$ & $\begin{array}{l}\Delta H_{\mathrm{c}} \\
\left(\mathrm{J} \mathrm{g}^{-1}\right)\end{array}$ & $\begin{array}{l}X_{\mathrm{c}} \\
(\%)\end{array}$ \\
\hline PP/PS blend (80/20) & 166.03 & 125.71 & 66.78 & 80.57 & 40.31 \\
Blend + 0.1 wt\% $x \mathrm{GnP}$ & 164.97 & 126.27 & 75.40 & 87.42 & 45.55 \\
Blend + 0.5 wt\% $x \mathrm{GnP}$ & 165.11 & 126.27 & 74.86 & 85.14 & 45.41 \\
Blend + 1 wt\% $x \mathrm{GnP}$ & 166.56 & 126.09 & 70.91 & 87.78 & 43.23 \\
Compatibilized blend & 166.30 & 124.92 & 55.94 & 68.37 & 40.52 \\
Blend + 0.1 wt\% $x \mathrm{GnP}$ & 164.96 & 125.12 & 55.07 & 69.54 & 39.92 \\
Blend + 0.5 wt\% $x \mathrm{GnP}$ & 165.48 & 125.44 & 55.04 & 67.93 & 40.03 \\
Blend + 1 wt $\%$ GnP & 164.97 & 125.30 & 56.21 & 68.41 & 41.05
\end{tabular}

little effect on the crystallization behavior of PP. This can be correlated with the phase morphology of the ternary system. As mentioned earlier, the ternary system exhibits an interpenetrating, co-continuous phase structure and $x \mathrm{GnP}$ nanoplatelets prefer to be dispersed in the soft SEBS phase. Thus $x \mathrm{GnP}$ has no direct contact with PP and therefore no influence on the rate of crystallization.

\section{Thermo gravimetric analysis}

The thermal degradation properties are evaluated from TGA thermograms (Fig. 8). It has been reported that graphene is capable of increasing the thermal stability of $\mathrm{PP}^{29}$ and PS. ${ }^{32}$ However, TGA results revealed that nanofillers have only marginal effect on the thermal stability of the composites. All systems showed single step degradation mechanism. Thermal degradation of composites are summarized in Fig. 9, in terms of parameters like initial degradation temperature (IDT), maximum degradation temperature (MDT) and final degradation temperature (FDT). The IDT and MDT of the PP/PS- $x \mathrm{GnP}$ composites remained unaltered, but the FDT was slightly improved by the incorporation of $x \mathrm{GnP}$. IDT and MDT values of ternary systems are greater than those of binary systems. This implies that the presence of SEBS in PP/PS blends has a sort of compatibilizing action; which stabilizes the phase morphology (as evidenced from SEM micrographs), improves the interfacial situation of the blends (as observed from mechanical and viscoelastic properties) retards the tendency of filler
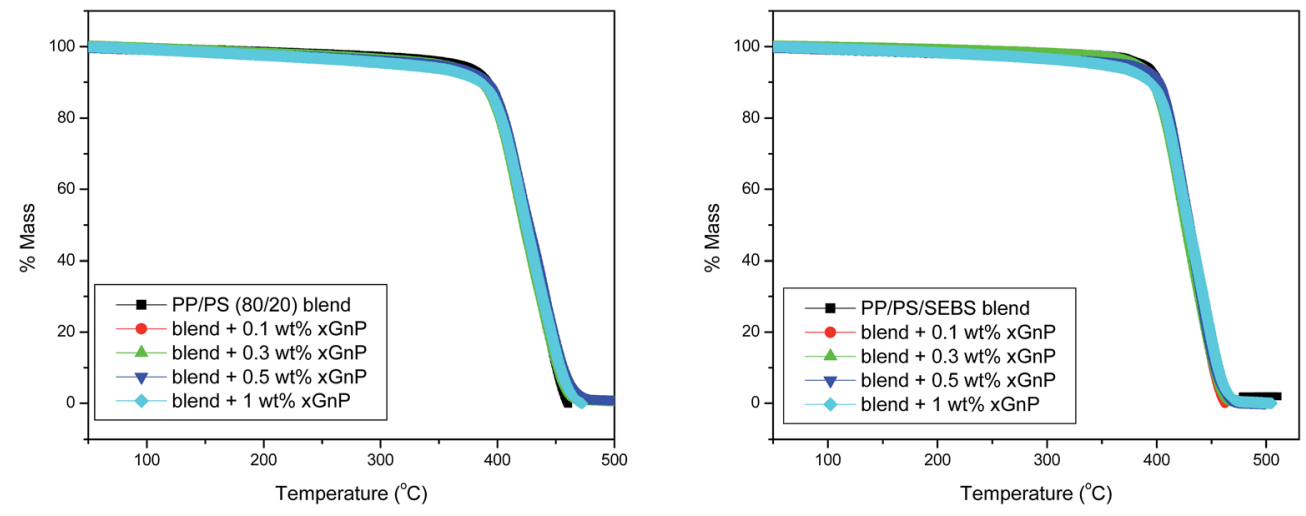

Fig. 8 TGA curves of (a) neat PP/PS blend and PP/PS $-x$ GnP composites (b) PP/PS-SEBS blends and PP/PS-SEBS $-x$ GnP composites. 


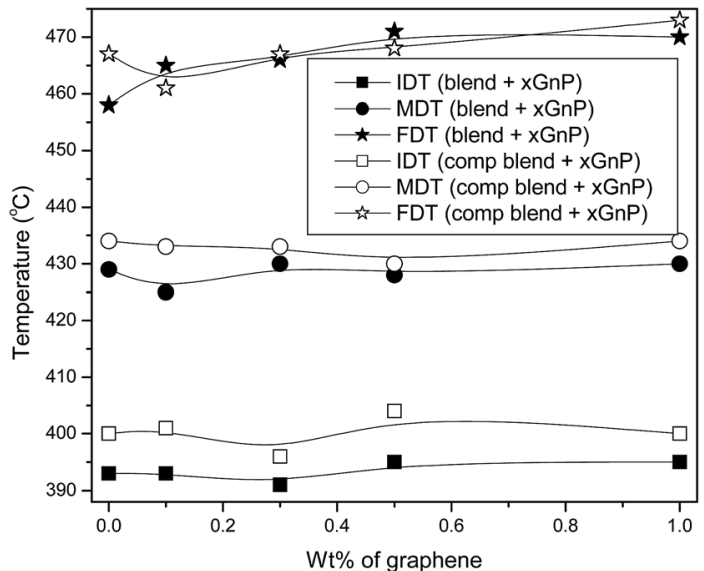

Fig. 9 IDT, MDT and FTD of PP/PS, PP/PS-SEBS, PP/PS $-x$ GnP and PP/ PS-SEBS $-x$ GnP systems.

agglomeration and refines dispersion of graphene platelets in SEBS phase.

\section{Conclusion}

Nanocomposites based on PP/PS blend and exfoliated graphene nanoplatelets $(x \mathrm{GnP})$ were prepared with and without SEBS and studied the mechanical, viscoelastic, thermal degradation and crystallization properties and phase morphology. It was observed that graphene nanoplatelets have no reinforcement effect in PP/PS blends, as they are not well dispersed in the blend or blend interface and contributed nothing towards the reduction of the unfavourable cross-correlations between PP and PS chains in the blend, which was supported by phase morphology studies. However, addition of SEBS into the blends made a dramatic change. PP/PS-SEBS- $x \mathrm{GnP}(0.1 \mathrm{wt} \%)$ exhibited good impact strength (ca. 140\% greater than PP/PS blends), excellent tensile elongation ( $c a$. 500\% greater than $\mathrm{PP} / \mathrm{PS}$ blend), reasonably good strength ( $c a .15 \%$ less than PP/PS blends) and stiffness ( $c a$. 25\% less than PP/PS blends). These results suggest that $\mathrm{PP} / \mathrm{PS}-\mathrm{SEBS}-x \mathrm{GnP}$ ( $0.1 \mathrm{wt} \%$ ) composite material is suitable for automotive applications. The incorporation of $x \mathrm{GnP}$ into this ternary system made significant impact as they diffused through the polymer chains, finely dispersed among soft SEBS segments and enhanced the overall stiffness of the system. The DMA results revealed an overall reduction in internal friction or improvement in damping behavior of the composites, in the presence of SEBS. It was also observed that graphene platelets at very low concentrations can act as effective nucleating sites for the crystallization of PP. The thermogravimetric analysis disclosed that the initial degradation temperature (IDT) and maximum degradation temperature (MDT) of composites increased in the presence of SEBS.

\section{Acknowledgements}

J P acknowledges the Department of Science and Technology, Government of India, for financial support under an Innovation in Science Pursuit for Inspired Research (INSPIRE) Faculty Award (contract grant number IFA-CH-16). N H acknowledges the funding from Australian Academy of Science under the Australia India Early Career Research Fellowship program.

\section{References}

1 J. Li, H. Li, C. Wu, Y. Ke, D. Wang, Q. Li, L. Zhang and Y. Hu, Eur. Polym. J., 2009, 45, 2619-2628.

2 A. A. Adewole, A. Denicola, C. G. Gogos and L. Mascia, $A d v$. Polym. Technol., 2000, 19, 180-193.

3 S. S. Morye, Polym. Eng. Sci., 2005, 45, 1369-1376.

4 S. S. Morye, Polym. Eng. Sci., 2005, 45, 1377-1384.

5 J. Parameswaranpillai, G. Joseph, R. V. Chellappan, A. K. Zachakariah and N. Hameed, J. Polym. Res., 2015, 22, 2, DOI: 10.1007/s10965-014-0641-y.

6 W. R. Waldman and M. De Paoli, Polym. Degrad. Stab., 2008, 93, 273-280.

7 X. Zhao, Y. Huang, M. Kong, Q. Yang and G. Li, RSC Adv., 2014, 4, 59302-59309.

8 N. Wang, N. Gao, Q. Fang and E. Chen, Mater. Des., 2011, 32, 1222-1228.

9 M. F. Díaz, S. E. Barbosa and N. J. Capiati, Polymer, 2005, 46, 6096-6101.

10 L. Caporaso, N. Iudici and L. Oliva, Macromolecules, 2005, 38, 4894-4900.

11 A. K. Gupta and S. N. Purwar, J. Appl. Polym. Sci., 1985, 30, 1799-1814.

12 P. H. P. Macaubas and N. R. Demarquette, Polymer, 2001, 42, 2543-2554.

13 A. Halimatudahliana, H. Ismail and M. Nasir, Polym. Test., 2002, 21, 263-267.

14 W. Brostow, T. H. Grguric, O. Olea-Mejia, D. Pietkiewicz and V. Rek, e-Polymers, 2008, 034.

15 G. P. Kar, S. Biswas and S. Bose, Phys. Chem. Chem. Phys., 2015, 17, 1811-1821.

16 Y. Cao, J. Zhang, J. Feng and P. Wu, ACS Nano, 2011, 5, 59205927.

17 R. Bahrami, T. I. Löbling, A. H. Gröschel, H. Schmalz, A. H. E. Müller and V. Altstädt, ACS Nano, 2014, 8, 1004810056.

18 S. Ye, Y. Cao, J. Feng and P. Wu, RSC Adv., 2013, 3, 79877995.

19 Y. Cao, J. Feng and P. Wu, J. Mater. Chem., 2012, 22, 1499715005.

20 F. You, D. Wang, X. Li, M. Liu, Z. M. Dang and G. H. Hu, J. Appl. Polym. Sci., 2014, 131, 40455, DOI: 10.1002/app.40455.

21 A. K. Krishnan, T. S. George, R. Anjana, N. Joseph and K. E. George, J. Appl. Polym. Sci., 2013, 127, 1409-1415.

22 L. Elias, F. Fenouillot, J. C. Majeste and P. Cassagnau, Polymer, 2007, 48, 6029-6040.

23 M. H. Al-Saleh and U. Sundararaj, Composites, Part A, 2008, 39, 284-293.

24 R. R. Tiwari and D. R. Paul, Polymer, 2011, 52, 1141-1154.

25 J. Parameswaranpillai, G. Joseph, K. P. Shinu, P. R. Sreejesh, S. Jose, N. V. Salim and N. Hameed, under review. 
26 M. A. Milani, D. González, R. Quijada, N. R. S. Basso, M. L. Cerrada, D. S. Azambuja and G. B. Galland, Compos. Sci. Technol., 2013, 84, 1-7.

27 K. N. Indira, P. Jyotishkumar and S. Thomas, Fibers Polym., 2014, 15, 91-100.

28 S. Zhao, F. Chen, C. Zhao, Y. Huang, J. Dong and C. C. Han, Polymer, 2013, 54, 3680-3690.

29 P. Song, Z. Cao, Y. Cai, L. Zhao, Z. Fang and S. Fu, Polymer, 2011, 52, 4001-4010.
30 M. El Achaby, F. Z. Arrakhiz, S. Vaudreuil, E. M. Essassi, A. Qaiss and M. Bousmina, J. Appl. Polym. Sci., 2013, 127, 4697-4707.

31 C. Vallés, A. M. Abdelkader, R. J. Young and I. A. Kinloch, Faraday Discuss., 2014, 173, 379-390.

32 A. S. Patole, S. P. Patole, H. Kang, J. B. Yoo, T. H. Kim and J. H. Ahn, J. Colloid Interface Sci., 2010, 350, 530-537. 